\title{
Ignorance is not an option
}

\author{
Tamela J. White BSN, MPH, JD ${ }^{1}$
}

ABSTRACT

Health literacy is a vital component in the design of public health interventions. Public understanding of health literacy and its role in attaining down stream and outcomes is not only a necessity but a moral mandate.
Author affiliations are listed at the end of this article.

Correspondence to: Tamela White, BSN, MPH, JD Farrell, White \& Legg, PLLC tjw@farrell3.com

\section{KEYWORDS}

health, literacy, Kaplan, intervention

Pick a town or region. On one side of the street in Flint, you can drink the tap water - on the other, lead contamination prohibits consumption. From the richest to poorest Baltimore county section, life expectancy varies as much as 20 years. ${ }^{1}$ The diabetes belt situate in 644 counties in 15 Southern and Appalachian states is inhabited by the most concentrated population of type 2 diabetics in the United States with its attendant chronic disease burden. ${ }^{2}$

Public health burdens begin with one - one occurrence. Temptation and access lead to occurrence. Tempting access is as innocent as graband-go processed food or alcohol sold at a local pharmacy or a prescription opioid-turned street drug. Temptations are ubiquitous. Access may or may not be.

Open your eyes while closing them in reflection upon the public health burdens around you.

While advances continue in the biomedical and genomic understanding of onset, treatment and prevention of disease, a key link in the public health promotion chain remains weak. That weak link is individual and community cognitive and spiritual understanding of health, referred to as health literacy.

Frightened, cold and alone. Tempted to explore a natural wonder following a day of dribbling, passing and shooting, the Taiwanese Wild Boar Soccer team accessed a cave. Little did they know what was to happen. Trapped. Cold. Alone.

International media covered the rescue minute by minute. A sophisticated engineering and scientific rescue was executed with calculated precision, analogous to biomedical, physiologic and genetic health research and intervention.

However, cave rescue and acute care hospitalization was not the end of the the story. Health care for each team member transitioned from intense medical assessment and treatment to health literacay. The critical pathway for recovery incorporated mental health, spiritual health and cognitive skill development. This carefully orchestrated careplan should be applauded as a shining health literacy investment in action as contemplated by models such 
as Kaplan et al's Multilevel Approach to Epidemiology Model of Health Policy Design and Intervention. ${ }^{3}$

Progressively, each boy and coach was reintroduced to normative comforts - favorite meals and personal treasures. Each was shepherded through a deliberate series of mental and spiritual decontamination. Confronting survivor's guilt, they visited the grave of a fallen hero. A respite with religious teachers and spiritual devotion occurred, designed as an anchor mental and spiritual healing.

Frightened. Cold. Alone. The victims of any acute or chronic illness crisis or of noxious personal encounters such as bullying or rape have the same crisis.

Huntington, West Virginia has a new Health Literacy Action plan in its war against addiction. Just as it rose from the ashes like a phoenix from the 1970 Marshall University football team plane disaster, the community has risen to the occasion and embraced health literacy. The cradle of the opiate epidemic, having the highest incidence nationwide of infants with neonatal abstinence syndrome ${ }^{3}$ and stubborn per capita increases in youth and adult drug-related deaths, Huntington's healthcare community has committed resources intended to empower victims to break addiction's cycle. PROACT, Provider Response Organization Addiction Care and Treatment, the first of its kind in the United States, integrates this health literacy mandate by addressing the "clinical, behavioral, spiritual and professional" needs of those affected by substance abuse. ${ }^{4}$

There exists a moral imperative in this debate about health care. These examples command our leaders to abandon defining health care as a commodity - what a hospital or doctor can "do for" or "give to" a "consumer" or "what you get" with your state, government or private pay health care plan or "entitlement."

Health care is not a system that miraculously fixes a problem.

Health care begins with one. It takes hard work work on the part of all and mostly, the compromised person. Any health care system must be redefined toward attention to the undeniable fact that access will always exist, temptations are everyday experiences and choices should be made with an understanding of consequences so that a choice by one does not become the choices of many.

Policymakers must redefine the issue. A downstream and upstream integrated healthcare system that embraces health literacy must be the goal, commitment and embraced as a moral imperative.

No phase of life, whether public or private, whether in business or in the home, whether one is working on what concerns oneself alone or dealing with another, can be without its moral duty; on the discharge of such duties depends all that is morally right, and on their neglect all that is morally wrong in life.

Cicero, 44 BCE

\section{AUTHOR AFFILIATIONS}

1. Farrell, White \& Legg, PLLC, Huntington, West Virginia

\section{REFERENCES}

1. World Health Organization: Monitoring Health for the Sustainable Goals, 2018 Annual Report, 2018; Bartolotta, D., Baltimore City Health Commissioner Dr. Leana Wen, Baltimore Health Department, CBS Baltimore, July 6, 2017, available at: https://baltimore.cbslocal. com/2017/07/06/life-expectancy-baltimore/ (last accessed Sept. 24, 2018).

2. Centers for Disease Control and Prevention, CDC Identifies Diabetic Belt. Dec. 1, 2017, available at: https://www.cdc.gov/diabetes/data/county.html (last accessed Oct. 3, 2018).

3. DHHR Releases Neonatal Abstinence Syndrome Data for 2017, West Virginia Department of Health and Human Services, https://dhhr. wv.gov/News/2018/Pages/DHHR-ReleasesNeonatal-Abstinence-Syndrome-Data-for-2017-. aspx.

4. Medical Institutions Form Substance Use Recovery Group, PROACT designed to serve needs of families, individuals, providers 
and community, The Leading Edge, Annual

Report 2017-2018, available at: https://www.

cabellhuntington.org. 
